\title{
Effect of Extrusion Speed on the Microstructure and Tensile Properties of AZ31 Alloy
}

\author{
Shengnan $\mathrm{YANG}^{1, \mathrm{a}}$, Wenyun $\mathrm{WU}^{1, b^{*}}$, Donghong $\mathrm{WANG}^{1, \mathrm{c}}$ \\ and Peiran DENG ${ }^{1, \mathrm{~d}}$ \\ ${ }^{1}$ School of Materials Engineering, Shanghai University of Engineering Science, Shanghai, 201620, \\ China \\ a360580689@qq.com¹, ${ }^{\mathrm{b}}$ wenyjlu@126.com, ${ }^{\mathrm{c} w d h c e t 6 @ 163 . c o m, ~}{ }^{\mathrm{d}}$ peirandeng@126.com
}

\begin{abstract}
The influences of extrusion speed on the microstructure and tensile properties of AZ31 alloy were investigated. The results suggested that the yield and tensile strength of AZ31 alloy decrease but elongation increases with the reduction of extruded speed. High speed extrusion produces fine grains with texture of $c$-axis perpendicular with extruded direction. The tension deformation is dominated by slip and the formed texture is obstructive for the basal slip, and also the inhomogeneous structure formed at high speed extrusion is harmful to the ductility. Samples extruded at low speed have comparatively homogeneous and coarse microstructure. Twinning provided more tension deformation and the lattice rotation induced by twinning is favorable for the activities of new slip systems, which induced the better ductility of AZ31 alloy.
\end{abstract}

\section{Introduction}

Use of light-weight magnesium alloys are according with the demand of better fuel economy and higher operating efficiency and its related reduction of exhaust gases in automotive applications [1]. Wrought Mg alloys have superior mechanical properties to cast $\mathrm{Mg}$ alloys. Extrusion in particular became of interest for the processing of $\mathrm{Mg}$ alloys, due to its technical and economic advantages in the production of structural components. This thermo-mechanical process of extrusion could induce grain refinement and texture formation then influence the alloys' mechanical properties [2]. The result of grain refinement is an effective way to enhance the yield strength based on the Hall-Petch effect. However, the mechanical property of $\mathrm{Mg}$ alloy is also affected by the texture, twinning and uniformity of the microstructure except for the average grain size [3]. Strong texture will form in the extrusion process due to the difference of critical resolved shear stress (CRSS) of the various slip systems. The plastic deformation of the extrusions has relationship with the formed texture in certain loading path. Twinning, as an important deformation mechanism of $\mathrm{Mg}$ alloy at low temperature, can accommodate the plastic strain and induce the revolution of initial texture [4]. And the change of texture has influence on the process of dislocation slip [5]. On the other hand, the taking place of twinning strongly depends on the grain size [6]. For Mg alloy extrusions, the forming speed is one of the important factors which influence the extent of the dynamic recrystallization (DRX) process [7]. So

* Corresponding author: 360580689@qq.com 
the mechanical properties of $\mathrm{Mg}$ alloy extrusions are mainly depended on the extruded speed. So far, systematic information about the relationship between extrusion speed and mechanical properties are relatively limited. The present paper was carried out to investigate the influence of extruded speed on the microstructure and tensile properties of the hot-extruded AZ31 alloy.

\section{Experimental Procedure}

The employed material is commercial AZ31 magnesium alloy. The chemical composition of the alloy is shown in table 1. As-cast AZ31 ingots with average grain size of $140 \mu \mathrm{m}$ are homogenized at $400^{\circ} \mathrm{C}$ for $12 \mathrm{~h}$ then cooled by fan. The extrusion ingots of $\varnothing 100$ $\mathrm{mm}$ are machined out from the homogenized ingots. Prior to extrusion, the extrusion ingots are heated to $400^{\circ} \mathrm{C}$ for $60 \mathrm{~min}$.

TABLE 1 CHEMICAL COMPOSITION OF AZ31 ALLOY TUBES (IN -WT.\%)

\begin{tabular}{cccccccc}
\hline alloy & $\mathrm{Al}$ & $\mathrm{Zn}$ & $\mathrm{Mn}$ & $\mathrm{Si}$ & $\mathrm{Ca}$ & $\mathrm{Fe}$ & $\mathrm{Mg}$ \\
\hline AZ31 & 3.1 & 0.82 & 0.34 & 0.02 & 0.04 & 0.002 & bal
\end{tabular}

The extrusion rod speeds are $30 \mathrm{~mm} / \mathrm{s}, 15 \mathrm{~mm} / \mathrm{s}$ and $1 \mathrm{~mm} / \mathrm{s}$ respectively. The dimension of the as-extruded alloy stick is $40 \mathrm{~mm}$ in diameter. Tensile specimens were machined along the longitudinal direction of the tubes. The tension tests were performed at room temperature on an AG-100KNA mechanical machine according to ASTM E21-92 (1999). The microstructure of initial tensile specimens and the samples after tension to fracture were analyzed using electron backscattered diffraction (EBSD). The specimen and the analytical direction are shown schematically in Fig. 1. Analysis was carried out using a $\mathrm{LEO}^{\mathrm{TM}} 1450$ scanning electron microscope operating at $20 \mathrm{KV}$ fitted with a TSL ${ }^{\mathrm{TM}}$ EBSD camera. The microstructures of tension samples near the fracture were analyzed through optical microscopy. The analytical surface was etched in aceticpicral $(10 \mathrm{ml}$ acetic acid + $4.2 \mathrm{~g}$ picric acid $+10 \mathrm{ml}$ water $+70 \mathrm{ml}$ ethanol $(99.5 \%))$.

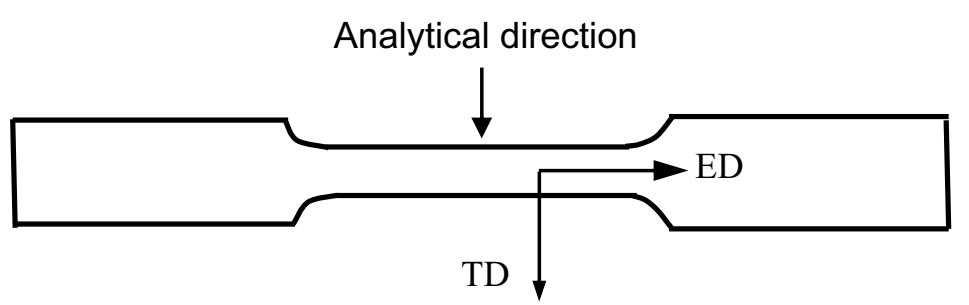

Fig. 1 Schematic diagram of the tensile sample and the direction for EBSD analysis

\section{Results}

Tensile properties of the tube extruded at different speeds are shown in Fig. 2. The results suggest that yield strength and tensile strength decrease with the reduction of extruded speeds, but the elongation has opposite results. 


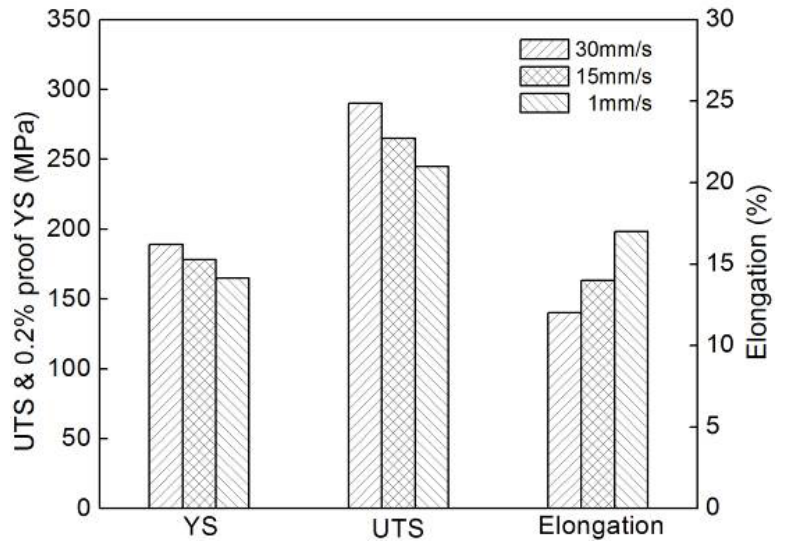

Fig. 2 Mechanical properties of AZ31 alloy at different extruded speed

Fig. 3 shows the IPF maps of samples extruded at various speeds. The results indicated that dynamic recrystallization (DRX) during extrusion is complete. The boundaries of most DRX grains are high angle grain boundaries (HAGBs) with their misorientation angles greater than $15^{\circ}$. And the grain size increases with the reduction of extruded speed. For the high speed extrusion, there are bands of stringers parallel to the extrusion direction, suggesting possible inhomogeneous deformation in these areas.

The pole figures (Fig. 4) show that there are ring basal textures with the $c$-axes of grains perpendicular to the extrusion direction (ED) in the three samples. And there are two components in the texture; one is that the $c$-axes of most grains are approximately parallel to the tangential direction
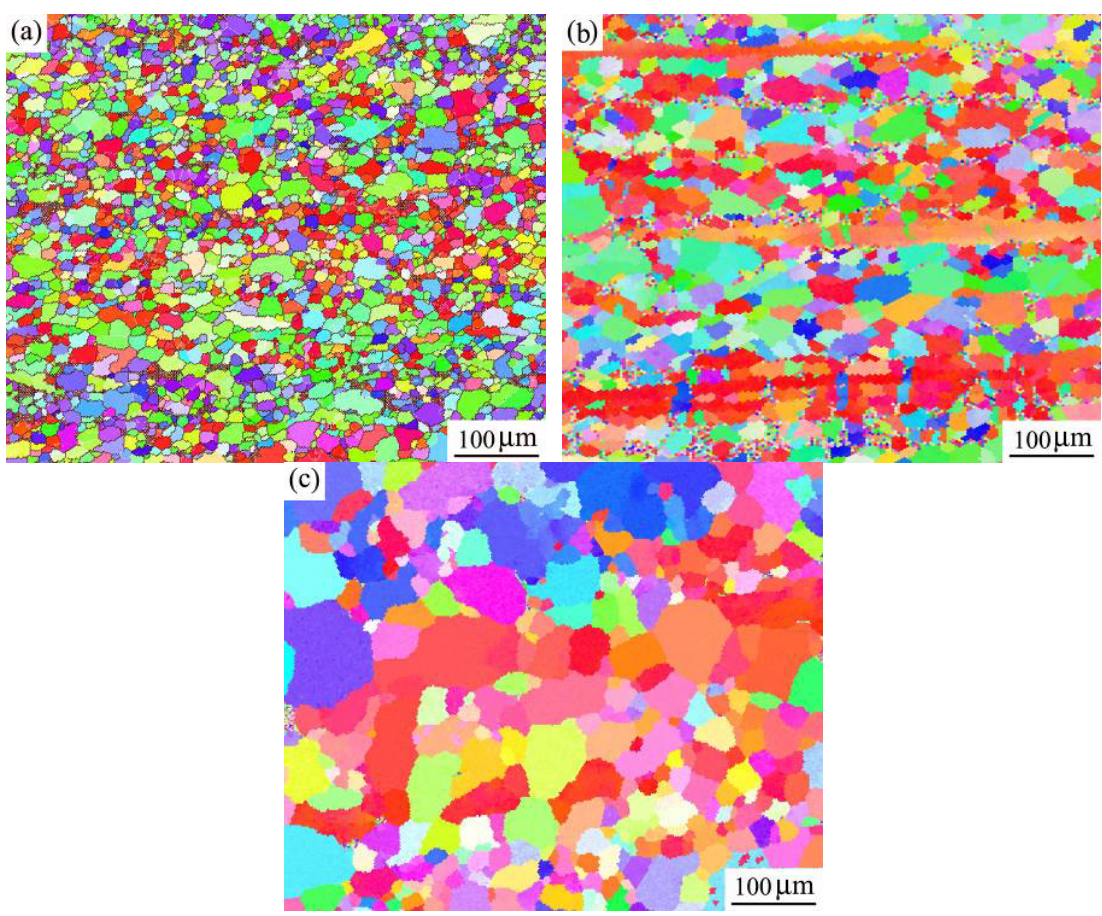

Fig. 3 Microstructure of AZ31 alloy extruded at (a) $30 \mathrm{~mm} / \mathrm{s}$, (b) $15 \mathrm{~mm} / \mathrm{s}$, (c) $1 \mathrm{~mm} / \mathrm{s}$

(namely TD component), and the other one is that $c$-axes approximately parallel to the 
radial direction (namely RD component). RD components are weaker and comparatively more dispersive in those samples.
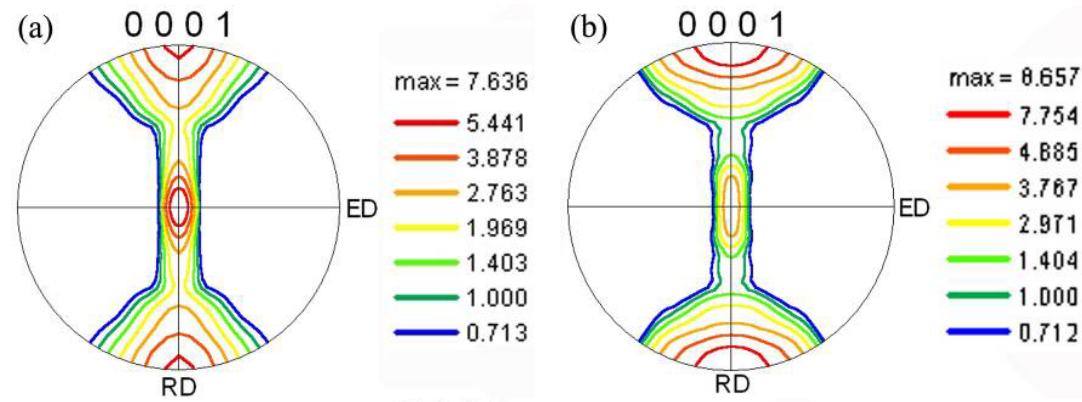

(c) 0001

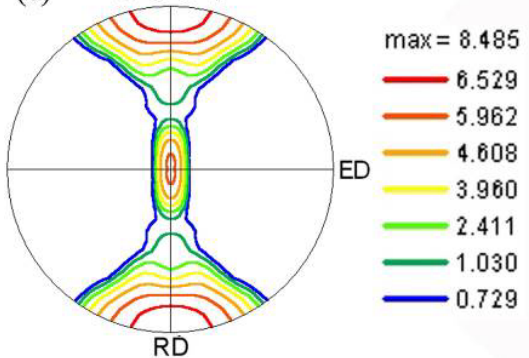

Fig. 4 Pole figures of alloy extruded at (a) $30 \mathrm{~mm} / \mathrm{s}$, (b) $15 \mathrm{~mm} / \mathrm{s}$, (c) $1 \mathrm{~mm} / \mathrm{s}$

Fig. 5 shows the microstructure near the tensile fracture of AZ31 alloy extruded at $30 \mathrm{~mm} / \mathrm{s}$. The IPF map (Fig. 5a) and grain boundary misorientation map (Fig. 5b) show that a number of low anglegrain boundaries (LAGBs) appeared, which must have been formed due to dislocation rearrangement inside the grains [13-15]. The grain shape map (Fig. 5c) shows some $\{10-12\}$ extension twins as well as a few $\{10-11\}$ contraction twins and $\{10-$ $11\}+\{10-12\}$ double twins appeared especially in the inhomogeneous areas where large grains exist.
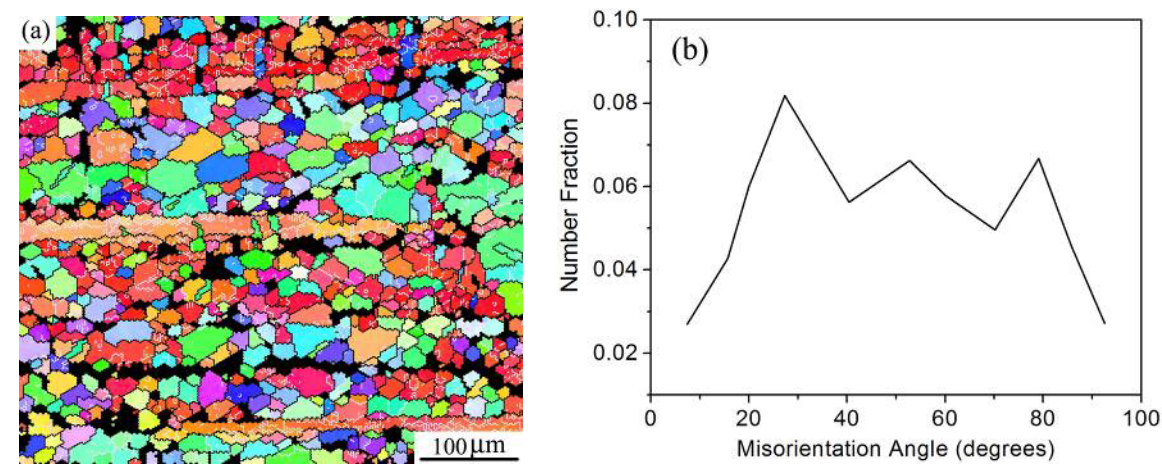


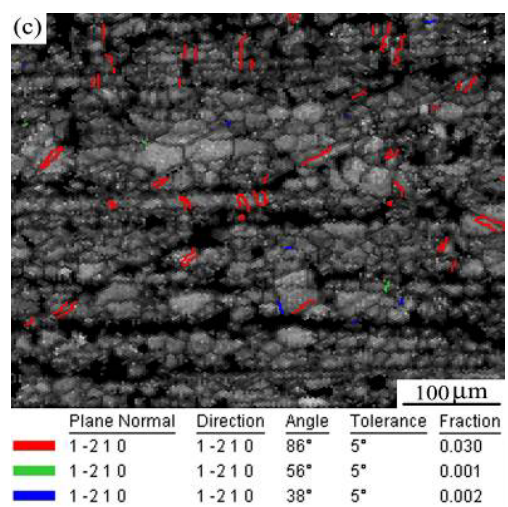

Fig. 5 Microstructure of the fractured sample from AZ31 alloy extruded at speed of $30 \mathrm{~mm} / \mathrm{s}$

Similar results were taken from the fracture samples of tubes extruded at low speeds as shown in Fig. 6. The IPF maps (Fig. 6a and b) suggested that local misorientation also took place inside the grains due to dislocation accumulation that rotates the lattice from point to point. More tension twins and compression twins appeared (Fig. 6c and d) due to the grains are larger comparing to the high speed extrusion, and the quantity of twins increased with the reduction of extrusion speed.
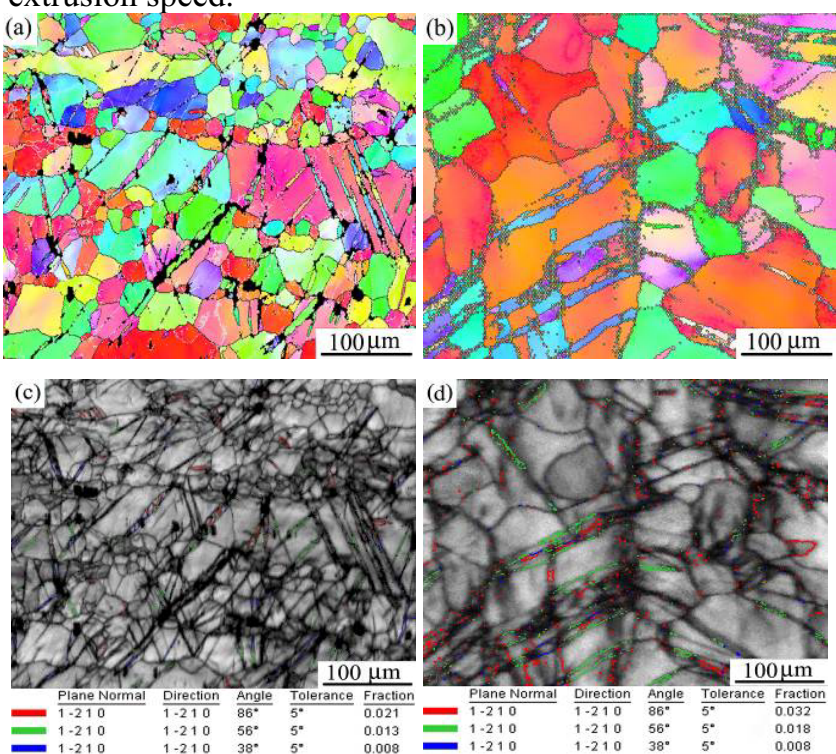

Fig. 6 Microstructure of the fractured samples (a) (c) extruded at $15 \mathrm{~mm} / \mathrm{s}$, (b) (d) $1 \mathrm{~mm} / \mathrm{s}$

Fig. 7 shows the texture of the samples after tension. The pole figures indicated that the grain orientations had not changed very much after tension, i.e., the $c$-axes of most grains are still perpendicular to the axial direction. The change of texture distribution is slightly more for the low speed extrusions due to more twins took place which induced the reorientation of the crystal. 

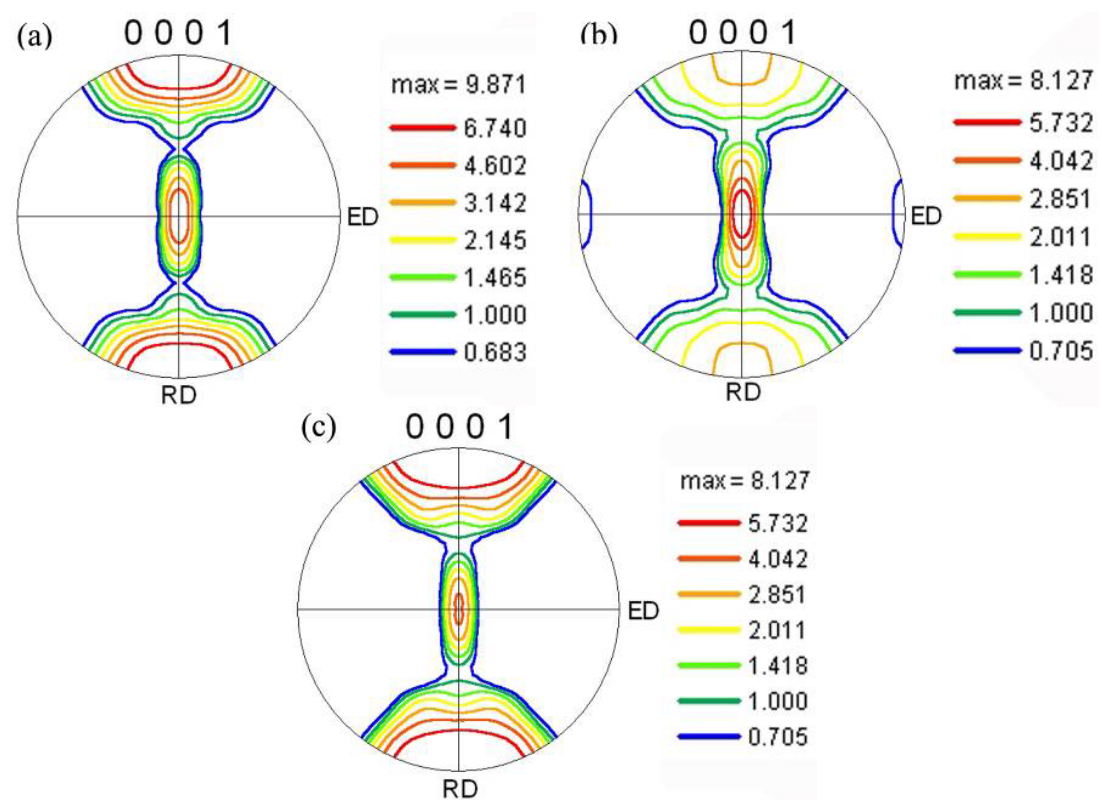

Fig. 7 Pole figures of the fractured tension samples, (a) $30 \mathrm{~mm} / \mathrm{s}$, (b) $15 \mathrm{~mm} / \mathrm{s}$, (c) $1 \mathrm{~mm} / \mathrm{s}$

Fig. 8 shows the microstructure of the samples near the tension fracture. Fig. 8a shows that the cracks are easy to nucleate at the interface between the fine grain and the coarse grain in the tube extruded at high speed, which will accelerate the failure of the materials during tensile test. For the samples extruded at $15 \mathrm{~mm} / \mathrm{s}$ and $1 \mathrm{~mm} / \mathrm{s}$, the cracks are nucleated as the grain boundaries or twin boundaries, and the distribution of the cracks is dispersed, which resulted in the better ductility.

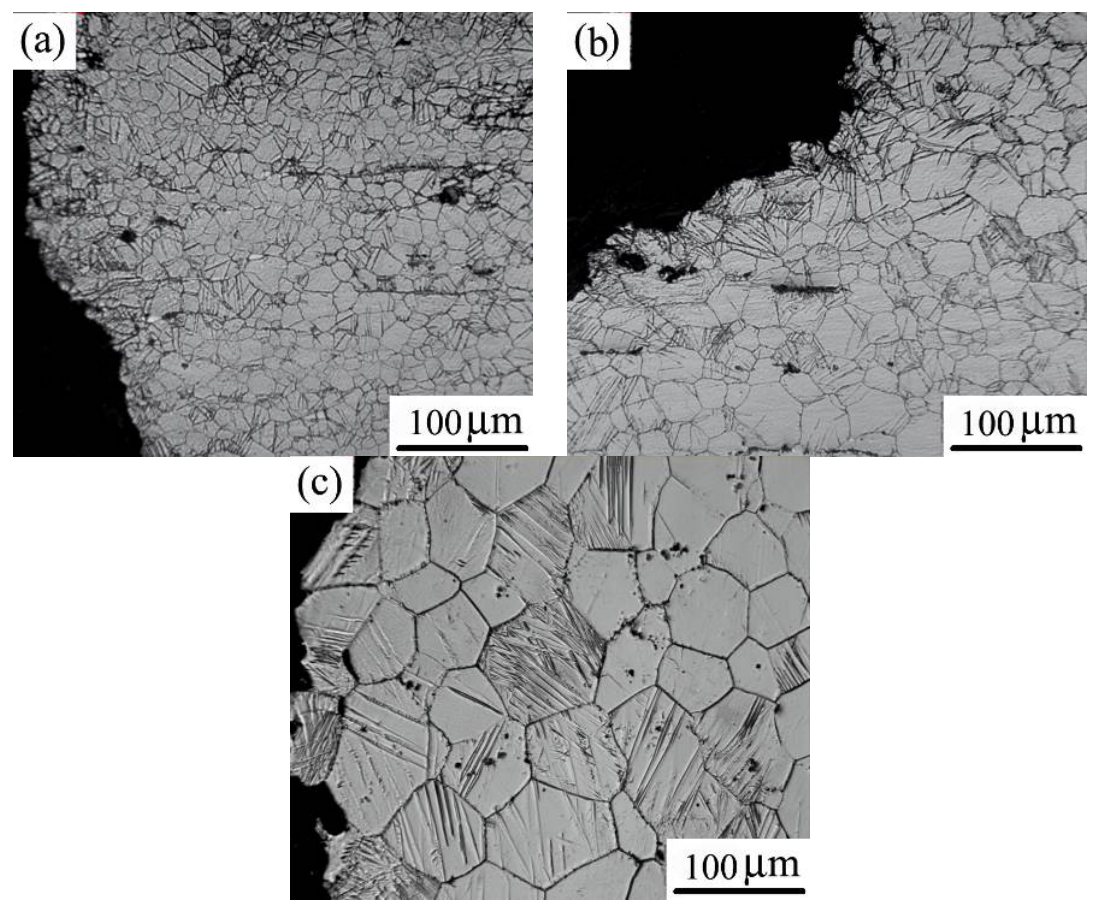

Fig. 8 Metallograph near the tension fracture, (a) $30 \mathrm{~mm} / \mathrm{s}$, (b) $15 \mathrm{~mm} / \mathrm{s}$, (c) $1 \mathrm{~mm} / \mathrm{s}$ 


\section{Discussion}

The extrusion deformation is a process of grain refinement due to DRX. The size of recrystallized grains has relationship with the deformation speed. Fine DRX grains together with inhomogeneous structure which is comprised with original coarse grains often formed at high speed. The grains grow up after DRX in enough time and form homogeneous structures. Two types of deformation modes, slip and twinning are observed in the test samples under tensile deformation. The activation of these deformation modes depends on the CRSS value, initial texture and grain size. At present condition the materials have strong textures, which obstacle the activation of dislocation slip on the basal slip system, and twinning became an important deformation mode. Three types of twins have been observed in the AZ31 alloy: extension twins, contraction twins and double twins. But the activation of twinning is strongly dependent on the grain size. The deformation under tension should be dominated by the dislocation slip. However, the initial orientation is unfavorable for the basal slip which can accommodate large strain. That's the reason for the high strength of sample extruded at $30 \mathrm{~mm} / \mathrm{s}$. A few twins were still observed in the bands of stringers which comprised with coarse grains. This inhomogeneous microstructure easily resulted in stress concentrated, which resulted in low elongation.

The microstructure became more uniform and the grain size increased correspondingly with the reduction of extrusion speed. The twins are easily activated in the coarse grains. So the deformation transited from slip dominated to twinning dominated. The twins play two important roles in the deformation process. It can be activated to induce stress relaxation before the action of basal slip as it is suppressed. So the yielding strength of the test sample is comparatively low. Furthermore, twinning induced the texture evolution through reorienting the crystal in the grains, which is generally more drastic than that by slip. The contraction twinning and double twinning can reorient the basal planes by $56^{\circ}$ and $38^{\circ}$ respectively. These reoriented areas are favorable for the taking place of new basal slips due to the decreasing of Schmid factor. The dispersive twins and its interaction with slips accommodate large strain under tension. That's the reason of good ductility for the low speed extrusions.

\section{Conclusion}

AZ31 alloy extruded at high speed has fine grains and high tension strength due to the slip dominated deformation and special texture. But the ductility is low owing to the inhomogeneous structure that results in stress concentration. Low extrusion speed can produce alloy with homogeneous and comparatively coarse microstructure, which have low tension strength and high ductility on account of the twinning dominated deformation and the interaction between twinning and slip.

\section{Acknowledgements}

This research was supported by the Startup Project (No. 2014-32) and the Postgraduate Innovation Project (No. 15KY0511) of Shanghai University of Engineering Science. 


\section{References}

1. A.A. Luo, Wrought Magnesium Alloys and Manufacturing Processes for Automotive Applications. Transactions-Journal of Materials and Manufacturing. SAE, PA, U.S.A. (2005) 411-421.

2. J. Bohlen, S.B. Yi, J. Swiostek, D. Letzig, H.G. Brokmeier, Microstructure and texture development during hydrostatic extrusion of magnesium alloy AZ31, Scr. Mater. 53 (2005) 259-264.

3. L. Jiang, J.J. Jonas, A.A. Luo, A.K. Sachdev, S. Godet, Influence of $\{10-12\}$ extension twinning on the flow behavior of AZ31 Mg alloy, Mater. Sci. Eng. A. 445446 (2007) 302-309.

4. Y.N. Wang, J.C. Huang, The role of twinning and untwinning in yielding behavior in hot-extruded Mg-Al-Zn alloy, Acta Mater. 55 (2007) 897-905.

5. S.B. Yi, C.H.J. Davies, H.G. Brokmeier, R.E. Bolmaro, K.U. Kainer, Deformation and texture evolution in AZ31 magnesium alloy during uniaxial loading, Acta Mater. 54 (2006) 549-562.

6. M.R. Barnett, A rationale for the strong dependence of mechanical twinning on grain size, Scr. Mater. 59 (2008) 696-698.

7. S.H. Hsiang, Y.W. Lin, Investigation of the influence of process parameters on hot extrusion of magnesium alloy tubes, J. Mater. Process. Technol. 192-193 (2007) 292299. 